\title{
On the Structure of 2-Methylenethiazolidin-4-ones
}

\author{
Cyano and $N$-Methyl Derivatives and Assignment of Geometrical \\ Configuration
}

\author{
OLOF CEDER and URBAN STENHEDE \\ Department of Organic Chemistry, University of Göteborg and Chalmers Institute of \\ Technology, F'ack, S-402 20 Göteborg 5, Sweden
}

\begin{abstract}
The isolation and configurational assignments (NMR) of the geometrical isomers $2 a$ and $2 b$ of 2-cyanomethylene-3-methylthiazolidin-4-one are reported and the exchange of the olefinic and methylene protons in the same system has been investigated by NMR. The mass spectrometrical fragmentation processes for the 2-cyano-, 2-carbethoxy-, and 2-carbomethoxymethylenethiazolidin4-ones and for their $N$-methyl derivatives are discussed.
\end{abstract}

Tn the preceding paper ${ }^{1}$ we described the isolation of two geometrical 1 isomers of both 2-carbethoxy- and 2-carbomethoxymethylenethiazolidin-4one, made preliminary assignments of geometrical configurations, which agreed with the findings of Taylor, ${ }^{2}$ and discussed the interconversion. The present communication reports similar results on 2-cyanomethylenethiazolidin4 -one, its $N$-methyl derivative, and the $N$-methyl-carbalkoxy-analog. NMR studies on the same compounds, which strengthen the earlier assignments of geometrical configuration, and a mechanism for the interconversion, based on deuterium-exchange experiments, are also discussed.

Condensation of malononitrile with ethyl mercaptoacetate, following the procedure of Satzinger, ${ }^{3}$ gave 2-cyanomethylenethiazolidin-4-one, 1, with the same properties as reported earlier. ${ }^{2,3}$<smiles>CCOC(=O)CS</smiles> 
The existence of $c$ is and trans carbalkoxy derivatives led us to expect the same kind of isomers of 1 , as was discussed by Taylor. ${ }^{2}$ All attempts to isolate two forms by fractional crystallization failed, however, and crystalline 1 showed a very sharp melting point, indicating a pure compound. The NMR spectrum (in dimethyl sulfoxide- $d_{6}$ ), containing two dominating, sharp bands at $4.03\left(\mathrm{CH}_{2} \mathrm{~S}\right)$ and $4.95(=\mathrm{CH}) \mathrm{ppm}$ and a broad amide-proton signal at $11.87 \mathrm{ppm}$, is in exact agreement with the expected structure. The resonance signals of the methylene and olefinic protons appear at slightly higher field than those of the carbethoxy compounds. Expansion of the signals in the spectrum of 1 did not reveal any fine structure and therefore no coupling is likely to exist among the protons in 1 . The mass spectrometrical fragmentation pattern will be discussed later.

There seems to be no obvious reason why the cyano compound should not form geometrical isomers, as does the carbethoxy compound, and Taylor, ${ }^{4}$ in fact, reports chemical shift values for the cis and trans forms of 1 . It is not clear, however, whether he tried to isolate them or whether he attempted a closer study of the interconversion. We suspected that the failure to isolate the isomers by fractional crystallization was due to a lower energy barrier for the isomerization. A freshly sublimed sample of 1 was dissolved in dimethyl sulfoxide and recording of a series of NMR spectra was started immediately. After $2 \mathrm{~min}$, four peaks at $4.95,4.82,4.03$, and $3.99 \mathrm{ppm}$ were present, but after $20 \mathrm{~min}$, two of them (4.95 and $4.03 \mathrm{ppm})$ dominated. This series of spectra clearly shows that in the crystalline state one form predominates and that in dimethyl sulfoxide solution a rearrangement to the other geometrical isomer takes place with a half life of $c a .4 \mathrm{~min}$, assuming a first or pseudo-first order reaction. The conversion also occurs in dimethylformamide and in pyridine at approximately the same rate. In these solvents the carbethoxy compound isomerizes much faster than the cyano analog. ${ }^{1}$ The assignments of geometrical configurations will be described in connection with the discussion of the $N$-methyl compounds (vide infra).

Methylation studies. Satzinger reported ${ }^{3}$ that 2 -cyanomethylenethiazolidin4-one, 1 , on methylation with dimethyl sulfate formed the $N$-methyl derivative 2 and that treatment of 1 with diazomethane in dimethylformamide-ether gave the $O$-methyl derivative, 3 . He also showed that dilute sodium hydroxide


rearranged the alleged enolic isomer 3 into 2 . Since such a process is difficult to visualize in basic medium, and since Satzinger's proposals were not supported by detailed spectral studies and, moreover, since there seemed to be no particular reason why $O$-methylation should occur in dimethylformamide with diazomethane in ether solution, we suspected that the two compounds isolated were instead the geometrical isomers $2 a$ and $2 b .^{5}$ 

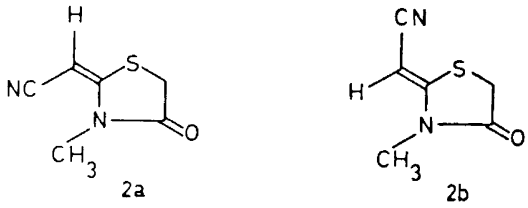

Treatment of 1 with dimethyl sulfate gave a methyl derivative, $2 b$, with a molecular weight of 154 (mass spectrometry) and an $M+2$ isotope peak of $5.3 \%$, in agreement with the molecular formula $\mathrm{C}_{6} \mathrm{H}_{6} \mathrm{~N}_{2} \mathrm{OS}$. The UV spectrum $\left(\lambda_{\max }=272 \mathrm{~nm} ; \varepsilon=18780\right)$ was almost identical with that of the starting material. Therefore, it seemed that no change of the chromophoric system had taken place. Addition of base to a solution of the compound caused no change in position or intensity of this absorption maximum, which shows that the $\mathrm{NH}$ group is absent. The IR spectrum displayed an amide band at $1725 \mathrm{~cm}^{-1}$ and the NMR spectrum (chloroform- $d$ ) contained a new methyl singlet at $3.15 \mathrm{ppm}$ in addition to the bands expected from the other protons in structure 2. Treatment of 1 with diazomethane in dimethylformamide yielded two compounds, one of which was identical with the dimethyl sulfate product discussed above. The ratio between the two products varied with the temperature at which the reaction was performed and the time between dissolution of 1 and addition of diazomethane. Room temperature and slow addition of diazomethane favored the formation of $2 b$, while low temperature, $0^{\circ} \mathrm{C}$, and an immediate, rapid addition of diazomethane favored the formation of the other product, $2 a$. This is to be expected since 1 isomerizes to the other geometrical isomer on dissolution in dimethylformamide. This reaction is rather slow $\left(t_{1 / 2}=30 \mathrm{~min}\right.$ at $\left.-5.5^{\circ} \mathrm{C}\right)$ compared to the reaction between 1 and diazomethane. The new compound, $2 a$, on treatment with dilute sodium hydroxide followed by dilute hydrochloric acid, rearranged to the other $N$-methyl compound, $2 b$. Treatment of $2 a$ with dilute sodium hydroxide only did not, however, cause the same rearrangement. The molecular weight (mass spectrometry) and $M+2$ isotope peak of the diazomethane product, $2 a$, corresponded to the molecular formula $\mathrm{C}_{6} \mathrm{H}_{6} \mathrm{~N}_{2} \mathrm{OS}$. The UV spectrum $\left(\lambda_{\max }=272 \mathrm{~nm} ; \varepsilon=18450\right)$, which remained unchanged on addition of base, was almost identical with that of the starting material. The IR spectrum displayed bands at 2208 (conjugated $\mathrm{CN}$ ), $1735(\mathrm{C}=\mathrm{O})$, and $1600 \mathrm{~cm}^{-1}$ $(\mathrm{C}=\mathrm{C})$. The NMR spectrum (chloroform- $d$ ) contained the methyl singlet now at $3.56 \mathrm{ppm}$ and the bands expected from the other protons in structure 2 (cf. Experimental). These observations leave no doubt that both the diazomethane and the dimethyl sulfate products are the $N$-methyl derivatives of 1 , and that they are geometrical isomers represented by structures $2 a$ and $2 b$.

The most striking dissimilarity between the NMR spectra of the isomers is the considerable difference in the chemical shifts of the $N$-methyl protons. The change seems to be too large to be caused only by opposite configurations. Molecular models (Dreiding) show that in $2 a$ the $N$-methyl group is located in the negative region of the anisotropic cone caused by the triple bond in the cyano group ( $c f$. Fig. 1). This circumstance could be responsible for the unusual

Acta Chem. Scand. 27 (1973) No. 6 



Fig. 1. Anisotropic regions in $2 a$ and $2 b$ induced by the $\mathrm{C} \equiv \mathrm{N}$ group.

difference in the chemical shifts observed.$^{6}$ In $2 b$ the methyl group lies outside the above-mentioned region (cf. Fig. 1). Based on these observations, we propose, that the $Z$ isomer ${ }^{7}(2 b)$ should represent the dimethyl sulfate product and the $E$ isomer ${ }^{7}(2 a)$ the diazomethane product which dominates at low reaction temperature. The application of the rule of Simon et al. ${ }^{8}$ gives the values 4.51 and $4.82 \mathrm{ppm}$ for the chemical shifts of the olefinic protons in $2 a$ and $2 b$, respectively. These are in agreement with the observed ones $(4.55$ and $4.78 \mathrm{ppm}$, respectively), but the differences between the calculated values and the observed ones are probably too small to allow a definitive assignment.

At room temperature, in a polar solvent like dimethyl sulfoxide, the pure $E$ isomer $2 a$ rearranged slowly to the $Z$ isomer $2 b$, as was the case with the $N$-norcompounds. At elevated temperatures $\left(180^{\circ} \mathrm{C}\right)$ a less polar solvent like $o$-dichlorobenzene effected the same conversion. Addition of a drop of trifluoroacetic acid at room temperature to a chloroform or an $o$-dichlorobenzene solution of the $E$ isomer $2 a$ immediately resulted in solutions containing $100 \%$ of the $Z$ isomer $2 b$. The purity of $2 a$ and also the isomer ratio were determined from the olefinic proton signals at 4.55 and $4.78 \mathrm{ppm}$, respectively. The results are summarized in Chart 1.

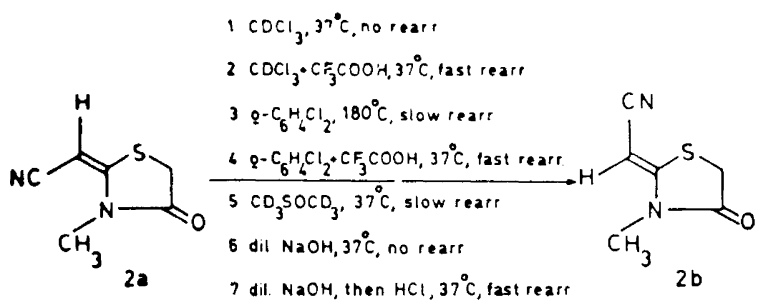

Chart 1.

Alkylation of the $Z$ and of the $E$ ethyl esters ${ }^{1}$ with dimethyl sulfate in ethanol-sodium carbonate gave one and the same product, which is expected, since the $E$ isomer rearranges to the $Z$ isomer in basic medium. Spectral properties proved the alkylation product to be the $N$-methyl derivative, and its properties agreed with those of the $N$-methyl compound reported by Satzinger $^{3}$ and by Taylor. ${ }^{2}$ Alkylation of the $E$ and $Z$ isomers with diazomethane 
in dimethylformamide yielded only one compound, which was identical with the one obtained from the dimethyl sulfate treatment. In no case could a second methylated isomer be detected. The $N$-methylated ethyl ester showed a molecular weight of 201 (mass spectrometry) corresponding to the molecular formula $\mathrm{C}_{8} \mathrm{H}_{11} \mathrm{NO}_{3} \mathrm{~S}$. The $\mathrm{UV}$ spectrum $\left(\lambda_{\max }=281 \mathrm{~nm} ; \varepsilon=21100\right)$ was almost identical with that of the starting material and therefore no change in the chromophore seemed to have occurred. On addition of base, the spectrum remained unchanged. The IR spectrum displayed carbonyl absorption at 1710 and $1660 \mathrm{~cm}^{-1}$. These observations definitely exclude the possibility of an $O$-methyl structure. The NMR spectrum contained a new methyl singlet at $3.17 \mathrm{ppm}$ and the NH signal had vanished. The chemical shift of the vinylic proton had been slightly shifted to 5.47 from $5.51 \mathrm{ppm}$ in the norcompound 4 , for which $Z$ configuration has been proposed. Since treatment of the $E$ isomer with base always yields $100 \%$ of the $Z$ isomer, it is reasonable to assume that the $N$-methyl derivative of 4 has the geometry pictured in 5 . The rule of Simon et al. predicts the value 5.33 for the olefinic proton in the $Z$ isomer 5 . This is in good agreement with the observed value of $5.47 \mathrm{ppm}$. On the basis of steric considerations, using molecular models (Dreiding), it is unlikely that the carbethoxy and the $N$-methyl groups could be accommodated on the same side of the double bond without disturbing the planarity of the chromophoric system. Since the UV spectra of $4,\left(\lambda_{\max }=283 \mathrm{~nm} ; \varepsilon=21500\right)$ and of $5\left(\lambda_{\max }=281 \mathrm{~nm} ; \varepsilon=21100\right)$ are virtually identical, one may assume that both compounds possess the same degree of planarity.


Exchange studies. To clarify the mechanism of the cis-trans isomerization, exchange experiments using $\mathrm{CDCl}_{3} / \mathrm{D}_{2} \mathrm{O}, \mathrm{CDCl}_{3} / \mathrm{TFA} / \mathrm{D}_{2} \mathrm{O}$, and $\mathrm{CDCl}_{3} / \mathrm{base} / \mathrm{D}_{2} \mathrm{O}$ were performed with the cyano and the $N$-methyl cyano compounds and with the ethyl ester and the $N$-methyl ethyl ester. The fast exchange of the $\mathrm{NH}$ and also of the $\mathrm{CH}_{2} \mathrm{~S}$ protons was expected since a number of cases have been reported where the methylene protons in thiazolidinones exchange easily in basic media and also condense with, e.g., benzaldehyde under the same conditions. ${ }^{9}$ It was further found that, in basic media such as pyridine $/ \mathrm{D}_{2} \mathrm{O}$ or $\mathrm{CDCl}_{3} /$ triethylamine $/ \mathrm{D}_{2} \mathrm{O}$, the olefinic proton exchanged rapidly in the NH-containing compounds 1 and 4 . The $N$-methylated compounds $2 a, 2 b$, and 5 , however, did not exchange the olefinic proton under the same conditions. Therefore, in basic media, the $\mathrm{NH}$ group must be involved in the exchange reaction, outlined below.

In the acidic medium $\mathrm{CDCl}_{3} / \mathrm{TFA} / \mathrm{D}_{2} \mathrm{O}$, the olefinic proton in the nonmethylated compound 4 exchanged rapidly. Due to low solubility in this solvent system, compound 1 could not be studied. The methylated compounds $2 b$ and 5 also exchanged the olefinic proton under the same conditions. The

Acta Chem. Scand. 27 (1973) No. 6 


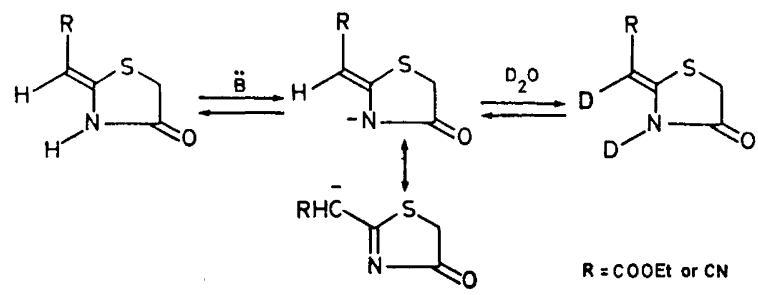

$Z$ isomers $2 b$ and 5 did not exchange the olefinic proton in dimethyl sulfoxide/ $\mathrm{D}_{2} \mathrm{O}$, while the $N$-norcompounds 1 and 4 rapidly exchanged this proton in the same solvent.

The isomerization of the $E$ isomer $2 a$ to the $Z$ isomer $2 b$ was studied in the same solvent systems. Under basic conditions $\left(\mathrm{CDCl}_{3} /\right.$ triethylamine $/ \mathrm{D}_{2} \mathrm{O}$, pyridine $/ \mathrm{D}_{2} \mathrm{O}$, or pyridine $/ \mathrm{D}_{2} \mathrm{O} / \mathrm{NaOD}$ ) $2 a$, which lacks the amide proton, did not isomerize. Satzinger ${ }^{3}$ claimed that base rearranges $2 a$ (which he pictures as the $O$-methyl derivative) to $2 b$, but we believe that the isomerization occurs when the reaction mixture is treated with acid (vide infra).

Under the acidic condition, $\mathrm{CDCl}_{3} / \mathrm{TFA} / \mathrm{D}_{2} \mathrm{O}, 2 a$ isomerizes to $2 b$ within a few seconds. The same conversion was effected by dimethyl sulfoxide $/ \mathrm{D}_{2} \mathrm{O}$, although at a much lower rate (50\% in $24 \mathrm{~h})$.

At least two possible mechanisms under acidic conditions can lead to isomerization of the $N$-methyl compounds.



If mechanism $\mathrm{I}$ is the only one operating, no exchange of the olefinic proton with deuterium should occur during the isomerization. If, instead, mechanism II is correct, deuterium should be found in $2 b$. In both $\mathrm{CDCl}_{3}$ / TFA $/ \mathrm{D}_{2} \mathrm{O}$ and in dimethyl sulfoxide $/ \mathrm{D}_{2} \mathrm{O}, 98 \%$ of deuterium was present in the $2 b$ formed. This atom of deuterium could be due to exchange in $2 b$ after it has been formed from $2 a$. We have, however, already reported above that in the solvent system dimethyl sulfoxide/ $\mathrm{D}_{2} \mathrm{O}$ the olefinic proton in $2 b$ was not substituted by deuterium, and from Table 1 it is evident that the rate of proton exchange is much lower than that of the formation of $2 b$ in 
2 - M E TH YLE NE T H I A O O I D I - 4 - O N E S

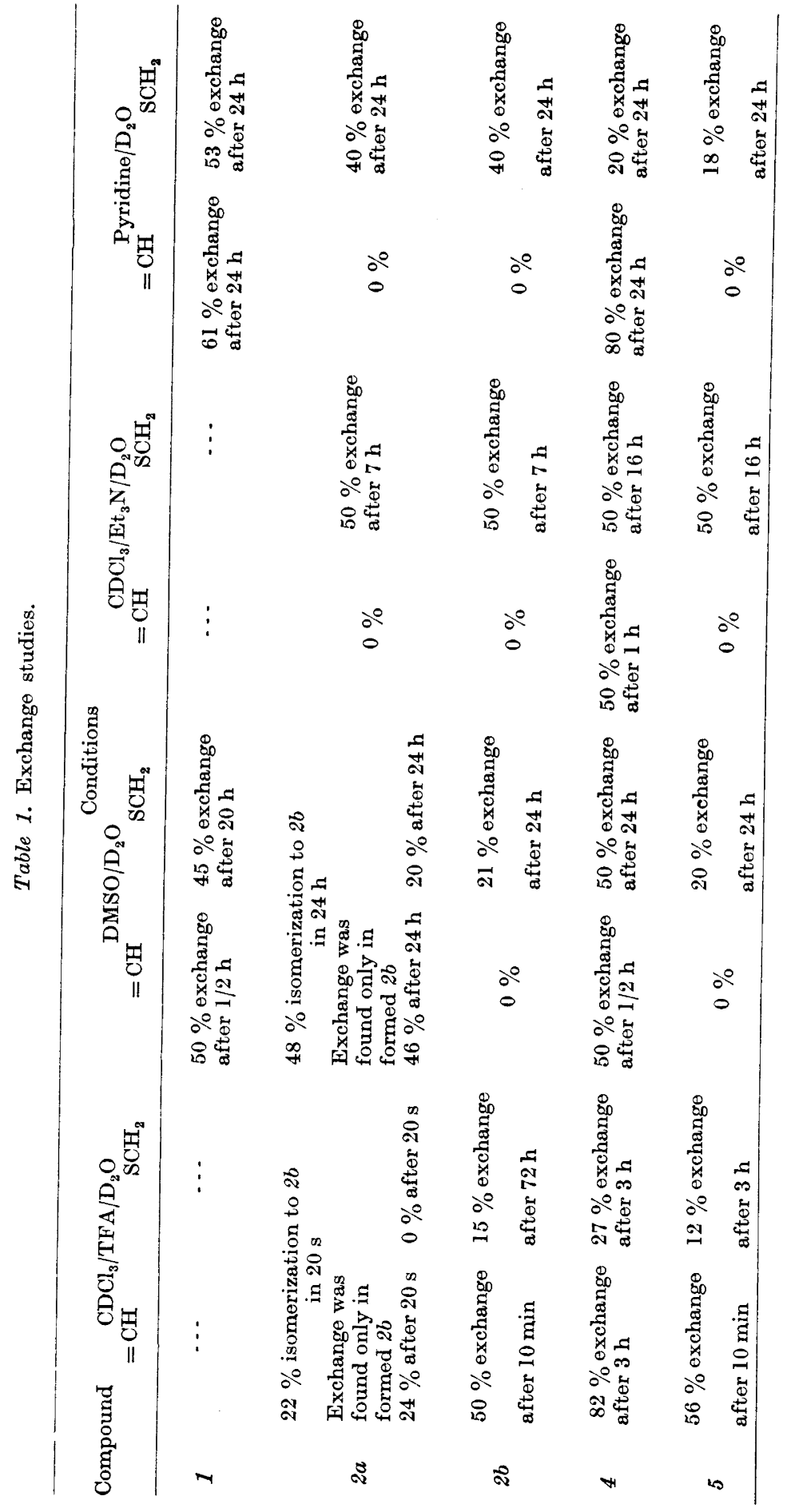


$\mathrm{CDCl}_{3} / \mathrm{TFA} / \mathrm{D}_{2} \mathrm{O}$. These observations lead us to believe that the isomerization and exchange proceed according to mechanism II, at least with the $N$-methylated cyano compound $2 a$. Taylor ${ }^{2}$ has proposed a mechanism similar to $I$ for the isomerization of the potassium salt of 2-carbethoxymethylenethiazoliain4-one. Our results are summarized in Table 1 where more detailed information about conditions, etc., can be found.

Mass spectrometrical studies. We now wish to discuss the mass spectrometrical fragmentation patterns of the compounds described in this and the preceding; communication. ${ }^{1}$ The spectra with assignments are reproduced



Fig. 2. Mass spectrum of $1\left(m^{*}=89.5\right)$.

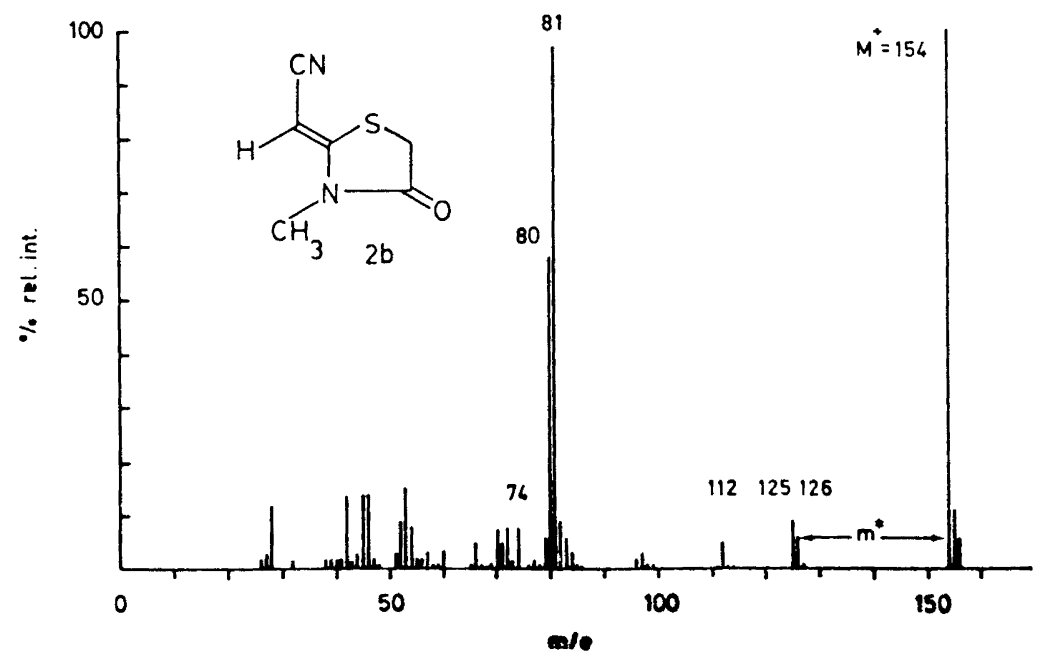

Fig. 3. Mass spectrum of $2 b\left(m^{*}=103.2\right)$.

Acta Chem. Scand. 27 (1973) No. 6 


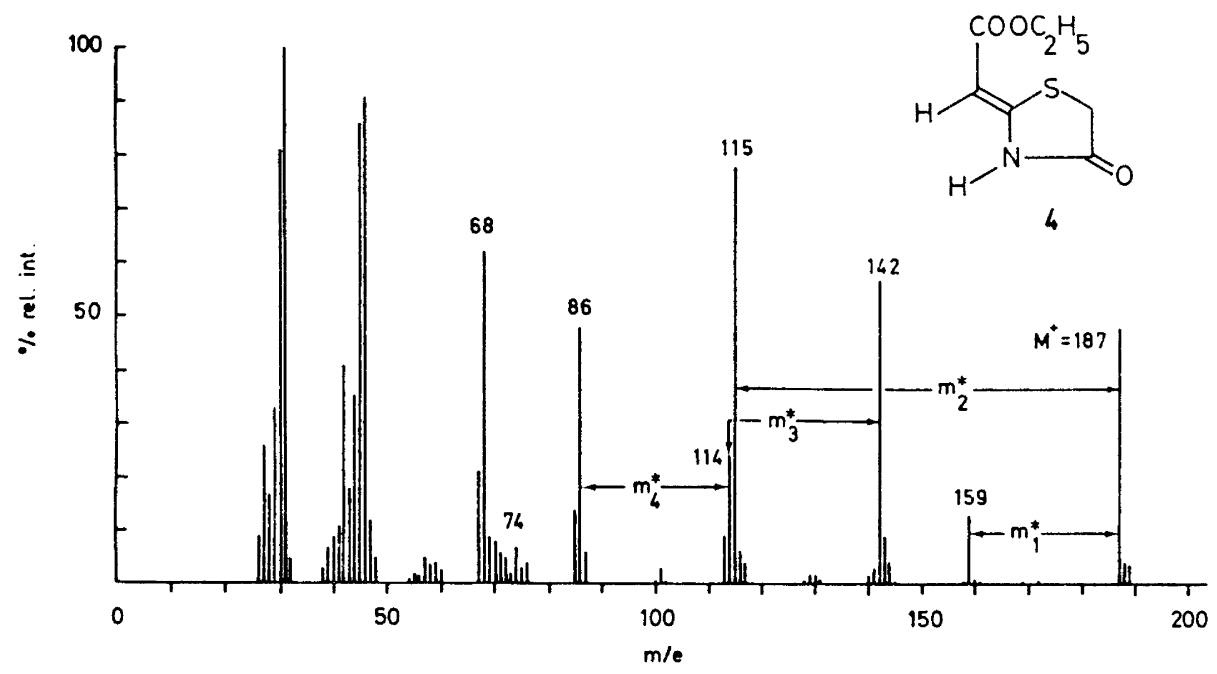

Fig. 4. Mass spectrum of $4\left(m_{1}^{*}=135.2, m_{2}^{*}=70.7, m_{3}^{*}=91.5\right.$, and $\left.m_{4}^{*}=64.9\right)$.

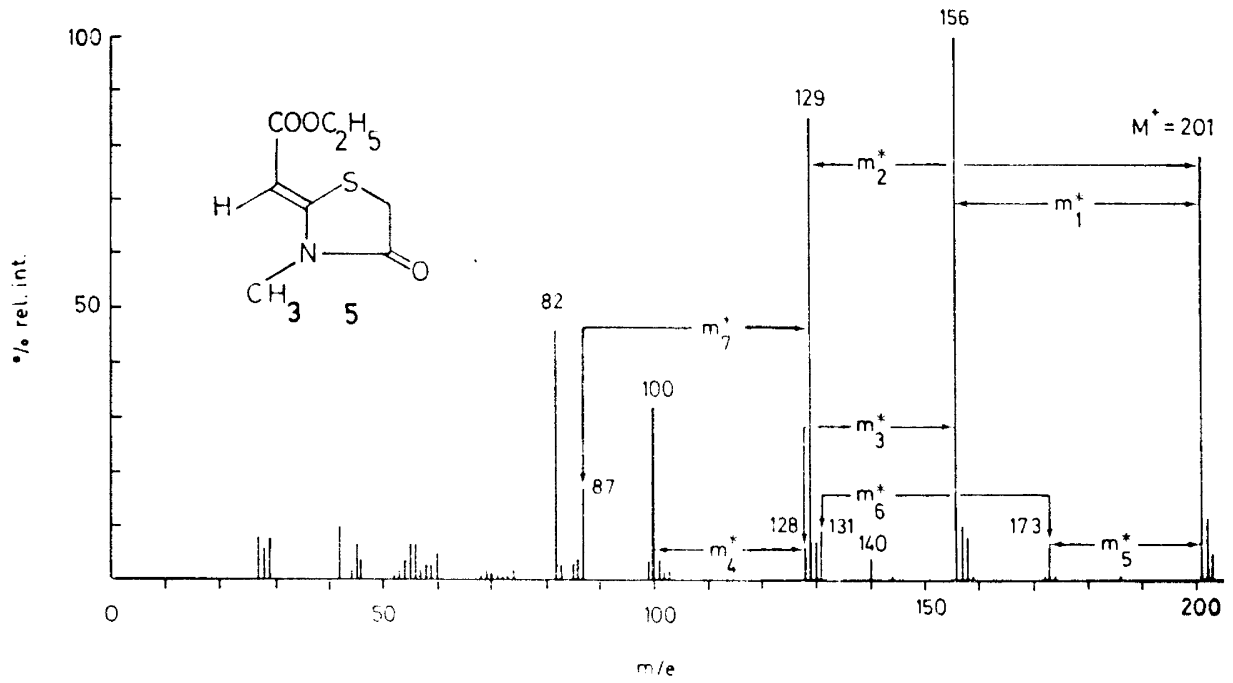

Fig. 5. Mass spectrum of $5\left(m_{1}{ }^{*}=121.1, m_{2}{ }^{*}=82.8, m_{3}{ }^{*}=105.0, m_{4}{ }^{*}=78.1, m_{5}{ }^{*}=148.9\right.$, $m_{8}^{*}=99.2$, and $\left.m_{7}^{*}=58.7\right)$.

in Figs. 2-7. Determination of exact masses confirmed the assignments of the molecular compositions of some of the individual fragments proposed in Charts 2-8 and in the text below. A number of fragmentation paths, supported by the presence of metastable ions, are indicated in the spectra and in the charts. As expected, ${ }^{10}$ the two geometrical isomers give identical mass spectra.

Acta Chem. Scand. 27 (1973) No. 6 




Fig. 6. Mass spectrum of $9 a\left(m_{1}^{*}=116.6, m_{2}^{*}=76.5, m_{3}^{*}=91.5\right.$, and $\left.m_{4}^{*}=64.9\right)$.



Fig. 7. Mass spectrum of $9 b\left(m_{1}^{*}=130.1, m_{2}^{*}=89.0, m_{3}^{*}=105.0, m_{4}^{*}=78.1, m_{5}^{*}=112.4\right.$, and $m_{6}{ }^{*}=58.7$ ).

All compounds show large molecular ion peaks, which in the cyano compounds are the base peaks. The $N$-methyl compounds give fragmentation patterns almost identical with those of the norcompounds, but displaced by 14 mass units.

The major fragmentation processes for the ethyl ester and its $N$-methyl homolog, 5, seem to be the ones usually found for ethyl esters, and loss of 45 and 72 mass units to form 6 and 7 , respectively, is observed. These peaks 
are of high intensity (base peaks in the spectra of 4 and 5). They also lose $28 \mathrm{mu}$, proved to be $\mathrm{C}_{2} \mathrm{H}_{4}$, to give 8 . The methyl ester, 9 , analogously loses 31,58 , and $14 \mathrm{mu}$ to form the ions 6,7 , and 8 , respectively. These reactions are outlined in Chart 2.

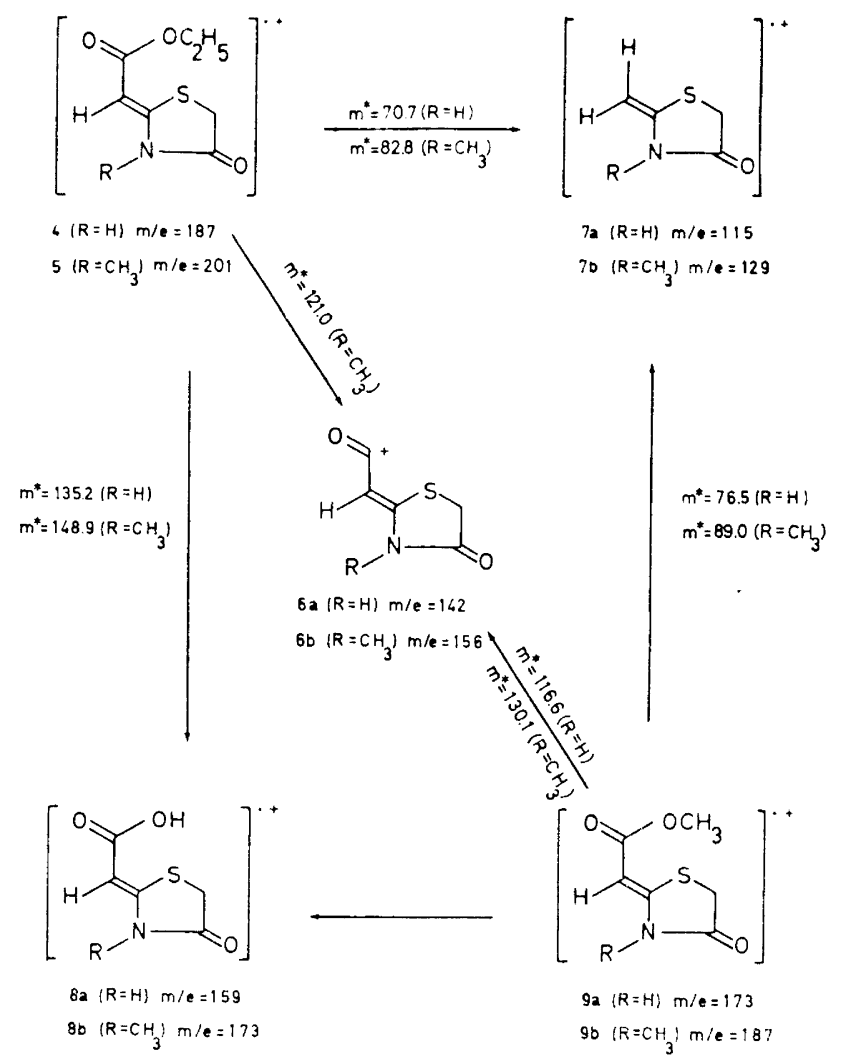

Chart 2.

Corresponding fragmentation in the cyano compounds, 1 and 2 , are prevented by the stability of the cyano group. The first ions formed are instead of type $10(\mathrm{M}-28), 11(\mathrm{M}-29)$, and $12(\mathrm{M}-42)$, as outlined in Chart 3. Their compositions are supported by exact mass measurements.

The ease of fragmentation in the ethyl ester group probably explains why no ion due to loss of the amide $\mathrm{CO}$ group can be detected, which was observed in the spectra of the cyano compounds (vide infra). The ion 6 , however, loses $28 \mathrm{mu}$ to yield 13 , which in turn again loses $28 \mathrm{mu}$ to form a fragment 


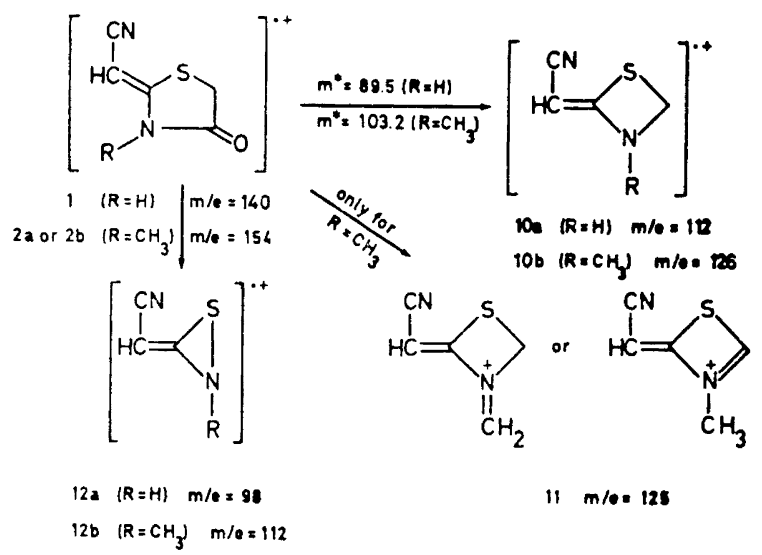

Chart 3.

for which we would like to propose the structure 14 . These transformations, which are supported by metastable ions, are outlined in Chart 4 . The elimination of the two $\mathrm{CO}$ groups could possibly take place in the reverse order.

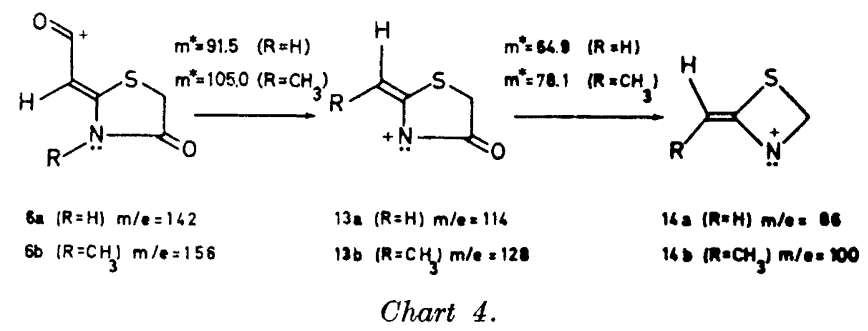

In the spectrum of the $N$-methyl compound 5 , metastable peaks are present at $m^{*}=58.7$ and 99.2, respectively, corresponding to the formation of the fragments 15 and 16 from $7 b$ and $8 b$, respectively. The metastable ion at $m^{*}=58.7$ is also present in the spectrum of the $N$-methyl compound $9 b$, but an ion at $m^{*}=99.2$ was not observed, probably because of the difficulty of generating ion $8 b$ from the $N$-methyl methyl ester $9 b$. These transformations are outlined in Chart 5 . In the spectrum of $9 b$, a metastable ion is also present at $m^{*}=112.4$, corresponding to the formation of the fragment 17 with the composition $\mathrm{C}_{5} \mathrm{H}_{7} \mathrm{NO}_{2} \mathrm{~S}$. The latter fragmentation process, outlined in Chart 5 , is analogous to the one that gave $m^{*}=99.2$ in the spectrum of the ethyl ester compound 5. In the ethyl ester it seems to be easier to first lose $\mathrm{C}_{2} \mathrm{H}_{4}$ to give $8 b$, and then $\mathrm{CH}_{2} \mathrm{CO}$ to give 16 , but in the $N$-methyl methyl ester, $9 b$, a direct loss of $\mathrm{CH}_{2} \mathrm{CO}$ to give 17 is observed. 


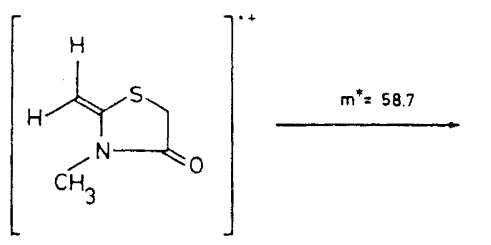

$7 \mathrm{~b} \mathrm{~m} / \mathrm{e}=129$<smiles>CN(C)CS</smiles>

$15 \mathrm{~m} / \mathrm{e}=87$



$8 \mathrm{~b} \mathrm{~m} / \mathrm{e}=173$<smiles>CSCC(=O)N(C)C</smiles>

$16 \mathrm{~m} / \mathrm{e}=13 i$

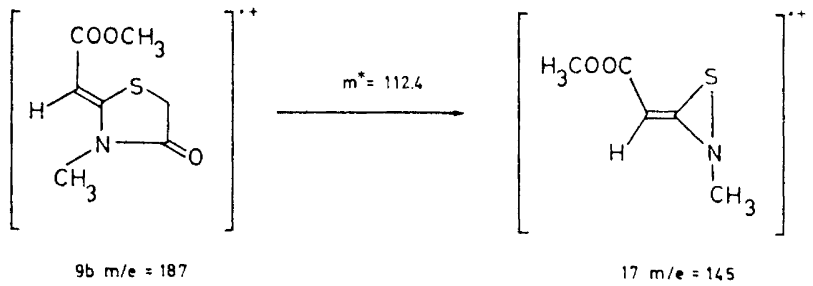

Chart 5 .

The peaks at $\mathrm{M}-73$ in the spectrum of the cyano compounds are the second highest ones $(55-98 \%$ of the base peaks). In the spectra of $1,2 a$, and $2 b$ these peaks have the compositions $\mathrm{C}_{3} \mathrm{H}_{3} \mathrm{~N}_{2}, \mathrm{C}_{4} \mathrm{H}_{5} \mathrm{~N}_{2}$, and $\mathrm{C}_{4} \mathrm{H}_{5} \mathrm{~N}_{2}$ respectively. For these we propose structures $18 a$ and $18 b$. In addition, the $\mathrm{M}-$ 73 peaks in the spectran of $2 a$ and $2 b$ contain an ion with the composition $\mathrm{C}_{4} \mathrm{H}_{3} \mathrm{NO}$. In the spectra of $1,2 a$, and $2 b$ ions are also present at $\mathrm{M}-74$ with the compositions $\mathrm{C}_{3} \mathrm{H}_{2} \mathrm{~N}_{2}, \mathrm{C}_{4} \mathrm{H}_{4} \mathrm{~N}_{2}$, and $\mathrm{C}_{4} \mathrm{H}_{4} \mathrm{~N}_{2}$. These fragments may have the structures $20 a$ and $20 b$ as indicated in Chart 6.

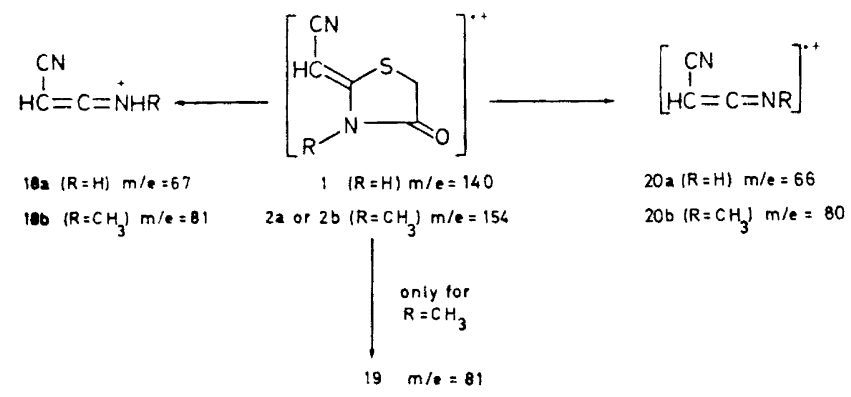

Chart 6. 
The spectra of $4,5,9 a, 9 b, 1$, and $2 a$ or $2 b$ contain an ion at $m / e=74$ with the composition $\mathrm{C}_{2} \mathrm{H}_{2} \mathrm{OS}$ for which structure 21 is proposed. This transformation is outlined in Chart 7.



Chart \%.

Compounds 4 and $9 a$ give rise to a peak at $m / e=68$ which has the composition $\mathrm{C}_{3} \mathrm{H}_{2} \mathrm{NO}$. The corresponding ion in the spectra of 5 and $9 b$ appears at $m / e=82$ and has the composition $\mathrm{C}_{4} \mathrm{H}_{4} \mathrm{NO}$. These fragments are probably formed by the loss of $\mathrm{CH}_{2} \mathrm{~S}$ from the ions $13 a$ and $13 b$, as outlined in Chart 8 .

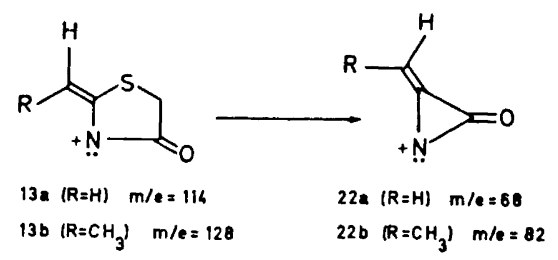

Chart 8 .

The fragment at $m / e=140$ in the spectrum of 5 has the composition $\mathrm{C}_{6} \mathrm{H}_{6} \mathrm{NOS}$. The fragment at $m / e=81$ with the composition $\mathrm{C}_{4} \mathrm{H}_{3} \mathrm{NO}$ in the spectrum of 1 is formed by the loss of HCNS from the molecular ion (cf. Fig. 2). We cannot propose any reasonable structures for these fragments.

\section{EXPERIMENTAL}

IR spectra were determined in $\mathrm{KBr}$ with a Beckman IR 9 spectrophotometer and UV spectra in ethanol with a Cary Model 15 spectrophotometer. The NMR spectra have been recorded with a Varian Model A - 60 spectrometer with tetramethylsilane as internal reference. The chemical shifts are reported in $\delta$-values. Mass spectra were recorded with a GEC-AEI 902 instrument at the Department of Medical Biochemistry, University of Göteborg. Melting points were determined with a Reichert melting-point microscope. Thin layer chromatography was carried out on Silica Gel GF $_{254}$ (Merck) according to Stahl.

Exchange experiments. The exchange experiments were generally performed in the following way. Two drops (ca. $0.05 \mathrm{ml}$ ) of deuterium oxide were added to an NMR tube containing $0.30 \mathrm{ml}$ of a $0.50 \mathrm{M}$ solution of the compound in question in the solvent system used in each case. When chloroform was used, two drops of triethylamine or trifluoroacetic acid were added immediately before the addition of the deuterium oxide. The solutions were then shaken for $5 \mathrm{~min}$ and NMR spectra were recorded at different times until possible exchange was observed. If no exchange could be detected after $72 \mathrm{~h}$,

Acta Chem. Scand. 27 (1973) No. 6 
the experiments were discontinued. In order to determine the rate of exchange in 2 cyanomethylenethiazolidin-4-one, 1, which contains only exchangeable protons, a weighed amount of sodium 2,2,3,3-tetradeuterio-3-trimethylsilylpropionate (TSP) was added to the NMR tube. The integral of the TSP signal $(\delta=0.00 \mathrm{ppm})$, which remained constant during the experiment, was used as a reference for the proton intensities. The results of these measurements are summarized in Table 1.

2-Cyanomethylenethiazolidin-4-one, 1, was prepared and isolated as described by Satzinger. ${ }^{3}$ Sublimation of recrystallized 1 yielded material (m.p. $185-187^{\circ} \mathrm{C}$, dec.) showing only one spot on thin layer chromatography (chloroform-ethyl acetate, 3:1; $\left.R_{F}=0.22\right)$. IR: $3110(\mathrm{NH}), 3070(=\mathrm{CH}), 2220(\mathrm{CN}), 1720(\mathrm{C}=\mathrm{O})$, and $1610 \mathrm{~cm}^{-1}(\mathrm{C}=\mathrm{C})$. UV: $\lambda_{\max }=272 \mathrm{~nm}(\varepsilon=18970)$. NMR (dimethyl sulfoxide- $\left.d_{6}\right)$ : singlet at $4.03\left(2 \mathrm{H}, \mathrm{SCH}_{2}\right)$, singlet at $4.95(1 \mathrm{H},=\mathrm{CH})$, and $\mathrm{NH}$ absorption at $11.87 \mathrm{ppm}$. MS, cf. Fig. 2.

Z-2-Cyanomethylene-3-methylthiazolidin-4-one, $2 b$, was prepared from 1 and dimethyl sulfate and isolated as described by Satzinger. ${ }^{3}$ Recrystallized product, m.p. $138-140^{\circ} \mathrm{C}$, showed only one spot on thin layer chromatography (chloroform-ethyl acetate, 3:1; $\left.R_{F}=0.41\right)$. IR: $3085(=\mathrm{CH}), 2206(\mathrm{CN}), 1725(\mathrm{C}=\mathrm{O})$, and $1580 \mathrm{~cm}^{-1}(\mathrm{C}=\mathrm{C}) . \mathrm{UV}: \lambda_{\max }=$ $272 \mathrm{~nm}(\varepsilon=18780)$. NMR (chloroform-d): singlet at $3.15\left(3 \mathrm{H}, \mathrm{NCH}_{3}\right)$, singlet at 3.94 $\left(2 \mathrm{H}, \mathrm{SCH}_{2}\right)$, and a singlet at $4.78(1 \mathrm{H},=\mathrm{CH})$. MS, $c f$. Fig. 3 .

E-2-Cyanomethylene-3-methylthiazolidin-4-one, $2 a$, was prepared and isolated according to a somewhat modified version of the method described by Satzinger. ${ }^{3}$ * His procedure was followed with the exception that ethereal diazomethane solution was added until an excess was present in the reaction solution. Thin layer chromatography (chloroformethyl acetate, $3: 1$ ) showed the presence of two components, $R_{F}=0.48$ and 0.41 . Twodimensional thin layer chromatography in the same solvent system indicated that the compound which had $R_{F}=\mathbf{0 . 4 8}$ rearranged on the chromatographic plate. If chloroformethyl acetate $(3: 1)$ containing $1 \%$ acetic acid was used as eluent, no rearrangement took place. The two products were separated using preparative thin layer chromatography in the last-mentioned solvent system. When $200 \mathrm{mg}$ of crude product was chromatographed, $60 \mathrm{mg}(30 \%)$ of each component was obtained. The slower-moving product was shown (NMR, TLC, and IR) to be identical with $Z$-2-cyanomethylene-3-methylthiazolidin-4-one, $2 b$, and the faster-moving component was found to be $E$-2-cyanomethylene-3-methylthiazolidin-4-one, $2 a$. The following data were recorded for $2 a$. M.p. $105-106^{\circ} \mathrm{C}$. IR: $3060(=\mathrm{CH}), 2208(\mathrm{CN}), 1735(\mathrm{C}=\mathrm{O})$, and $1600 \mathrm{~cm}^{-1}(\mathrm{C}=\mathrm{C})$. UV: $\lambda_{\max }=272 \mathrm{~nm}(\varepsilon=18450)$. NMR (chloroform-d): singlet at $3.56\left(3 \mathrm{H}, \mathrm{NCH}_{3}\right)$, singlet at $3.87\left(2 \mathrm{H}, \mathrm{SCH}_{2}\right)$, and singlet at $4.55 \mathrm{ppm}(1 \mathrm{H},=\mathrm{CH})$. MS, $c f$. Fig. 3 .

2-Carbomethoxymethylene-3-methylthiazolidin-4-one, $9 b$, was prepared from 2-carbomethoxymethylenethiazolidin-4-one, $9 a,{ }^{1}$ and diazomethane, as described for $2 a$. The desired product, $9 b$, could also be obtained from $9 a$ and dimethyl sulfate, as described for $2 b$. White crystals, m.p. $159-161^{\circ} \mathrm{C}$, were obtained by recrystallization from ethanol. Thin layer chromatography (chloroform-ethyl acetate, 3:1) showed only one component $\left(R_{F}=0.44\right)$. IR: $3070(=\mathrm{CH}), 1715$ (amide $\left.\mathrm{C}=\mathrm{O}\right), 1690$ (ester $\mathrm{C}=\mathrm{O}$ ), and $1595 \mathrm{~cm}^{-1}$ $(\mathrm{C}=\mathrm{C})$. UV: $\lambda_{\max }=282 \mathrm{~nm}(\varepsilon=19950)$. NMR (chloroform-d): singlet at $3.15(3 \mathrm{H}$, $\left.\mathrm{NCH}_{3}\right)$, singlet at $3.73\left(2 \mathrm{H}, \mathrm{SCH}_{2}\right)$, singlet at $3.75\left(3 \mathrm{H}, \mathrm{OCH}_{3}\right)$, and singlet at $5.58 \mathrm{ppm}$ (1H, $=\mathrm{CH})$. MS, $c f$. Fig. 7 .

2-Carbethoxymethylene-3-methylthiazolidin-4-one, 5, was prepared and isolated in the same way as was $9 b$. Both methods gave only one component (thin layer chromatography; chloroform-ethyl acetate, $3: 1 ; R_{F}=0.55$ ). M.p. $96-97^{\circ} \mathrm{C}$. IR: $3080(=\mathrm{CH}$ ), 1715 (amide $\mathrm{C}=\mathrm{O}), 1680$ (ester $\mathrm{C}=\mathrm{O})$, and $1575 \mathrm{~cm}^{-1}\left(\mathrm{C}=\mathrm{C}\right.$ ). UV: $\lambda_{\max }=281 \mathrm{~nm}(\varepsilon=21100)$. NMR $($ chloroform- $d)$ : triplet $(J=7.0 \mathrm{~Hz})$ at $1.28\left(3 \mathrm{H}, \mathrm{CH}_{3}\right)$, singlet at $3.17\left(3 \mathrm{H}, \mathrm{CCH}_{3}\right)$, singlet at $3.73\left(2 \mathrm{H}, \mathrm{SCH}_{2}\right)$, quartet $(J=7.0 \mathrm{~Hz})$ at $4.19\left(2 \mathrm{H}, \mathrm{OCH}_{2}\right)$, and singlet at $5.47 \mathrm{ppm}$ $(1 \mathrm{H},=\mathrm{CH})$. MS, cf. Fig. 5 .

Acknowledgments. Financial support from the Swedish Natural Science Research Council and from the grant Främjande av ograduerade forskares vetenskapliga verksamhet to the University of Göteborg is gratefully acknowledged. We thank Mrs. Inger Nilson for technical assistance.

* Satzinger claims that this compound is the $O$-methyl ether, 3.

Acta Chem. Scand. 27 (1973) No. 6 


\section{REFERENCES}

1. Ceder, O., Stenhede, U., Dahlquist, K.-I., Waisvisz, J. M. and van der Hoeven, M. G. Acta Chem. Scand. 27 (1973) 1914.

2. Taylor, P. J. Spectrochim. Acta A 26 (1970) 153.

3. Satzinger, G. Ann. Chem. 665 (1963) 150.

4. Cf. p. 159 in Ref. 2.

5. Cf. p. 160 in Ref. 2 .

6. Mathieson, D. W. Nuclear Magnetic Resonance for Organic Chemists, Academic, London 1967, p. 38.

7. IUPAC Tentative Rules for the Nomenclature of Organic Chemistry, Section E, Fundamental Stereochemistry; J. Org. Chem. 35 (1970) 2849.

8. Matter, U. E., Pasqual, C., Pretsch, E., Pross, A., Simon, W. and Sternhell, S. Tetrahedron 25 (1969) 691.

9. Elderfield, R. C. Heterocyclic Compounds, Wiley, New York 1957, Vol. 5, p.714.

10. Meyerson, S. and Weitcamp, A. W. Org. Mass Spectrom. 1 (1968) 659.

Received January 11, 1973. 